\title{
Cooling effect of an urban park by enhanced heat transport efficiency
}

\author{
Masahito UeYAma $^{\mathrm{a}, \uparrow}$ and Tomoya ANDO ${ }^{\mathrm{a}}$ \\ ${ }^{a}$ Graduate School of Life and Environmental Sciences, Osaka Prefecture University, \\ 1-1 Gakuen-cho, Naka-ku, Sakai, Osaka 599-8531, Japan \\ )
}

\begin{abstract}
The mitigation of the urban heat island effect is an important environmental issue for sustainable urban development. We quantified the relative contributions to surface cooling associated with land use changes from an urban center to an urban park using the temperature decomposition method, with one-year paired eddy covariance measurements in Sakai, Japan. The enhanced heat transport efficiency achieved through park creation decreased daytime surface temperatures by 3.9-4.9 K, which was the greatest contribution to daytime surface cooling throughout the season. The disappearance of anthropogenic heat flux due to park creation reduced nighttime surface temperatures by $0.1-0.6 \mathrm{~K}$, which was the greatest contribution at night in summer months. Enhancing heat transport efficiency through urban greening is thus a good mitigation strategy for cooling urban surfaces.
\end{abstract}

Key words: Eddy covariance, Land cover change, Local climate, Perturbation analysis, Surface energy exchange

\section{Introduction}

Human-induced land cover change alters surface energy exchange, resulting in changes in local and regional climate. The urban heat island (UHI) phenomenon is the most commonly known problem that alters surface energy exchange (Oke et al., 2017). UHI was first detected in terms of surface air temperatures measured within the urban canopy layer at fixed points (Landsberg, 1981) but was recently detected in terms of surface temperatures (skin temperatures often measured by remote sensing) and air temperatures above the urban boundary layer (Oke et al., 2017). The differences in the UHI effects could be due to different processes at the microscale for surface temperature UHIs, at the local scale for surface air temperature UHIs, and at the local to mesoscale for boundary layer temperatures (Oke et al., 2017).

The intensity of the UHI is determined by superimposed changes in multiple radiative and biophysical factors. Zhou et al. (2016) found, that in China, the magnitudes of the daytime UHI intensities for surface temperatures were greater in cities located in regions with higher precipitation, suggesting the importance of evaporative cooling in surrounding regions. Other factors also play important roles in the UHI effect, including changes in evaporation (Taha, 1997), heat transport efficiency (Zhao et al., 2014), surface albedo (Kolokotroni and Giridharan, 2008), and anthropogenic heat (Ichinose et al., 1999). The relative contributions of these factors are currently under debate and could depend on the cities (Cao et al., 2016; Zhao et al., 2014). To date, the direct measurements of surface energy exchange for elucidating the detailed mechanisms of the UHI effect are lacking.

Urban parks are often cooler than surrounding cities and are thus often known as park cool islands (Spronken-Smith and Oke, 1998). Air temperatures in urban parks were found to be up to $5 \mathrm{~K}$ lower than those in their surroundings (Chen et al.,

Received; April 8, 2020

Accepted; June 11, 2020

†Corresponding author: ueyama@envi.osakafu-u.ac.jp

DOI: 10.2480 /agrmet.D-20-00022
2012; Sugawara et al., 2016; Spronken-Smith and Oke, 1998). Factors contributing to park cooling effects are low heat storage, tree shade (Hamada and Ohta, 2010), and evaporative cooling (Spronken-Smith et al., 2000). The cool island phenomenon has been measured in urban parks, but the detailed mechanisms of cooling have still not been quantitatively evaluated.

The consequence of land use change on the local climate has been evaluated by analyzing the surface energy balance (Bright et al., 2015). The temperature decomposition method is a kind of linear perturbation analysis that utilizes paired measurements of surface energy exchange from contrasting land cover types in the same region (Lee et al., 2011). This method quantifies the contributions of each biophysical component to surface cooling and warming by land use change (Cao et al., 2016; Chen and Dirmeyer, 2016; Zhao et al., 2014). Zhao et al. (2014) combined this method with an earth system model and clarified that the UHI for surface temperatures in North America was mostly caused by reduced heat transport efficiency $(3.0 \pm 0.3 \mathrm{~K}$ warming) in the daytime under humid climates and by large heat storage (approximately $1-2 \mathrm{~K}$ warming) at night in all climate zones. The application of this method with direct flux measurements could be helpful in clarifying the role of urban green space and providing effective mitigation plans for UHIs.

Eddy covariance measurements provide direct estimates of surface energy exchange in urban areas (Ando and Ueyama, 2017; Grimmond and Oke, 1999; Moriwaki and Kanda, 2004). Compared with those in natural and managed ecosystems, eddy covariance measurements are limited in urban areas, partly due to the difficulty of deploying instrumentation in urbanized areas (Oke et al., 2017), resulting in uncertainties in the urban surface energy balance. Consequently, perturbation analysis, which is often conducted using eddy covariance measurements in ecosystem studies (Juang et al., 2007; Stoy et al., 2006), is not conducted in urban areas. The direct measurements of surface energy exchange could improve our understanding of the surface energy balance in urban areas.

In this study, we clarified the surface cooling mechanism of urban parks based on surface energy balance measurements in a dense urban built-up area (Ando and Ueyama, 2017) and 
a forested urban park (Ueyama and Ando, 2016) in Sakai, Japan. We quantified the relative contributions to the daytime and nighttime surface cooling associated with land use change from a dense urban built-up area to a large park (hereafter, park creation) using the temperature decomposition method. The estimated surface cooling is for surface temperature rather than air temperature, because translating surface to air temperature change could depend on the spatial scale of land cover change. Thus, the estimated cooling in this study is the upper limit of the expected air temperature change near the surface (Juang et al., 2007).

\section{Methods}

\subsection{Sites and observations}

We measured surface energy fluxes and environmental variables at two urban locations in Sakai, Osaka, Japan (Ando and Ueyama, 2017; Ueyama and Ando, 2016). The Sakai City Office (SAC) site $\left(34^{\circ} 34^{\prime} 25^{\prime \prime} \mathrm{N}, 135^{\circ} 28^{\prime} 59^{\prime \prime} \mathrm{E}\right)$ is located in a dense urban built-up area comprising both residential and commercial buildings. The mean building height is $10.7 \mathrm{~m}$, but buildings higher than $20 \mathrm{~m}$ are an average of $36 \mathrm{~m}$ high (Ando and Ueyama, 2017). Plan area index for buildings is 0.33 . Oizumi Ryokuchi (IZM) $\left(34^{\circ} 33^{\prime} 48^{\prime \prime} \mathrm{N}\right.$, $\left.135^{\circ} 32^{\prime} 1^{\prime \prime} \mathrm{E}\right)$ is a large urban park, 101.5 hectares in size, located $4 \mathrm{~km}$ east of SAC. The eddy covariance and meteorological observations at SAC were conducted on a tower on the roof of the Sakai City Office (111 $\mathrm{m}$ above ground level). The measurements at IZM were conducted on a tower (30 m above ground level) located at the eastern edge of the park. Supporting meteorological and environmental variables were also measured on the roof of a building at Osaka Prefecture University $\left(34^{\circ} 32^{\prime} \mathrm{N}, 135^{\circ} 30^{\prime} \mathrm{E}\right)$ within the city. Details for the three sites, instrumental setup, analyses, and general characteristics of turbulent fluxes have been described by Ueyama and Ando (2016) and Ando and Ueyama (2017).

\subsection{Data analysis}

We estimated the surface cooling associated with park creation using the temperature decomposition method (Lee et al., 2011; Zhao et al., 2014). This method separates the contributions to surface temperature change into individual drivers: surface albedo $(\alpha)$, aerodynamic resistance to heat $\left(r_{a}\right)\left(\mathrm{s} \mathrm{m}^{-1}\right)$, Bowen ratio $(\beta)$, storage heat flux $\left(Q_{S}\right)\left(\mathrm{W} \mathrm{m}^{-2}\right)$, and anthropogenic heat flux $\left(Q_{F}\right)\left(\mathrm{W} \mathrm{m}^{-2}\right)$. The surface temperature changes $\left(\Delta T s_{\text {calc }}\right)$ associated with park creation can be decomposed as

$$
\begin{aligned}
& \Delta T_{\text {calc }} \approx \frac{-\lambda_{0}}{1+f} R_{s d} \Delta \alpha+\frac{-\lambda_{0}}{(1+f)^{2}}\left(Q^{*}-Q_{S}+Q_{F}\right) \Delta f_{1} \\
& +\frac{-\lambda_{0}}{(1+f)^{2}}\left(Q^{*}-Q_{S}+Q_{F}\right) \Delta f_{2}+\frac{-\lambda_{0}}{1+f} \Delta Q_{S}+\frac{-\lambda_{0}}{1+f} \Delta Q_{F} \\
& +\frac{-\lambda_{0}}{1+f} \Delta R_{s d}+\frac{-\lambda_{0}}{1+f} \Delta R_{l d},
\end{aligned}
$$

where $\lambda_{0}=1 / 4 \sigma T s^{3}$ is the local climate sensitivity $\left(\mathrm{K} \mathrm{W}^{-1} \mathrm{~m}^{2}\right)$, $\sigma$ is the Stefan-Boltzmann constant $\left(5.67 \times 10^{-8} \mathrm{~J} \mathrm{~m}^{-2} \mathrm{~s}^{-1} \mathrm{~K}^{-4}\right)$, $f(>0)$ is the energy redistribution factor, $R_{s d}$ is the downward shortwave radiation $\left(\mathrm{W} \mathrm{m} \mathrm{m}^{-2}\right), R_{l d}$ is the downward longwave radiation $\left(\mathrm{W} \mathrm{m}^{-2}\right), Q^{*}$ is the net radiation $\left(\mathrm{W} \mathrm{m}^{-2}\right)$, and $\Delta$ is the land cover change effect, which is represented by the values at IZM minus those at SAC. $f, \Delta f_{1}$, and $\Delta f_{2}$ are expressed as

$$
\begin{aligned}
& f=\frac{\rho_{a} c_{p}}{4 r_{a} \sigma T_{s}^{3}}\left(1+\frac{1}{\beta}\right) \\
& \Delta f_{1}=\frac{-\lambda_{0} \rho_{a} c_{p}}{r_{a}}\left(1+\frac{1}{\beta}\right) \frac{\Delta r_{a}}{r_{a}}
\end{aligned}
$$

and

$$
\Delta f_{2}=\frac{-\lambda_{0} \rho_{a} c_{p}}{r_{a}} \frac{\Delta \beta}{\beta^{2}},
$$

where $\rho_{a}$ is the air density $\left(\mathrm{kg} \mathrm{m}^{-3}\right)$ and $c_{p}$ is the specific heat $\left(1004 \mathrm{~J} \mathrm{~K} \mathrm{~kg}^{-1}\right)$. In Eq. 1, the terms on the right side are the surface temperature difference between the urban built-up area and the urban park associated with the difference in surface albedo (term 1), heat transport efficiency (term 2), evaporation (term 3), heat storage (term 4), anthropogenic heat emissions (term 5), downward shortwave radiation (term 6), and downward longwave radiation (term 7). In this study, we neglected terms 6 and 7 , because the two sites were located less than $4 \mathrm{~km}$ apart; thus, the averaged downward radiations were assumed to be the same.

The qualified sensible and latent heat fluxes (Ando and Ueyama, 2017; Ueyama and Ando, 2016) were used for the period from January 28, 2015 to March 10, 2016. We eliminated the low turbulence data when the friction velocity was less than $1.0 \mathrm{~m} \mathrm{~s}^{-1}$. Based on the flux footprint model (Kormann and Meixner, 2001), we only used data in which more than $80 \%$ were contributed by urban areas for SAC (Ando and Ueyama, 2017) and 50\% were contributed by the urban park for IZM (Ueyama and Ando, 2016). For analysis in IZM, we chose the relaxed criterion to increase data coverage. Despite the relaxed criterion, the qualified data showed a clear biological signal, such as daytime $\mathrm{CO}_{2}$ uptake (Ueyama and Ando, 2016), and thus, could be used as a flux at the urban park. The flux divergence of the sensible heat flux between the surface and the measurement height was estimated based on a storage flux by air temperature at the height of $111 \mathrm{~m}$ and found to be $17 \%$ on average at the SAC site. Nevertheless, we did not correct this effect, because a single point measurement could not represent the heterogeneous air temperatures and humidity within the flux footprint. We only used the non-gap-filled eddy covariance data for the temperature decomposition method; thus, Eq. 1 was only applied for the periods when the paired data were available at the two sites.

The aerodynamic resistance to heat $\left(r_{a}\right)$ was estimated by the logarithm law, which is expressed as

$$
r_{a}=\frac{1}{k u_{*}}\left[\ln \left(\frac{z-d}{z_{m}}\right)+\ln \left(\frac{z_{m}}{z_{h}}\right)-\psi_{\mathrm{h}}\left(\frac{z-d}{L}\right)\right],
$$

where $k$ is the von Kármán constant $(=0.4), u_{*}$ is the friction velocity $\left(\mathrm{m} \mathrm{s}^{-1}\right), z$ is the measurement height $(\mathrm{m}), d$ is the displacement height $(\mathrm{m}), z_{m}$ is the roughness length for momentum $(\mathrm{m}), z_{h}$ is the roughness length for heat $(\mathrm{m}), \psi_{\mathrm{h}}$ is the integrated stability function for heat, and $L$ is the Obukhov length (m). Because the measurement height in SAC (111 m) was much higher than that in IZM $(30 \mathrm{~m})$, the value of $z$ in IZM was adjusted to $111 \mathrm{~m}$ when calculating $r_{a}$ using Eq. 5. For SAC, $d$ and $z_{m}$ were estimated by the method proposed by Kanda et al. (2013), considering the vegetative fraction (0.11; Ando and Ueyama, 2017) (Kent et al., 2017): $d=19.5 \mathrm{~m}$ and $z_{m}=1.78 \mathrm{~m}$. For estimating the plan area index for the vegetative surface, we used 
a constant leaf-on value of 0.2 for the aerodynamic porosity due to the lack of information on evergreen/deciduous fraction at the site. This value could overestimate $d$ and $z_{m}$, but the overestimates were minimal because of the low vegetative fraction (Kent et al., 2017). The plan area index, including vegetation, was calculated as 0.42 for SAC. For IZM, $d$ and $z_{m}$ were estimated at 0.7 and 0.1 times the mean tree height $(12.3 \mathrm{~m})$, respectively.

To estimate aerodynamic resistance to heat, we calculated the value of $k B^{-1}$, which is defined as $\ln \left(z_{m} / z_{h}\right)$. For SAC, we used a model for $k B^{-1}$ (Kanda et al., 2007), which was developed using turbulent flux measurements at an idealized miniature city that consisted of an aligned array of $1.5 \mathrm{~m}$ concrete cubes over a $100 \mathrm{~m} \times 50 \mathrm{~m}$ concrete surface. For IZM, the value of $k B^{-1}$ was the weighted mean of each land cover from the literature for each land cover type: 2.25 for vegetation (Garratt, 1994; Ma et al., 2008), 4.0 for bare soil (Ma et al., 2008), and the model value (Kanda et al., 2007) for concrete. The areal fractions in IZM were 0.74 for vegetation, 0.07 for bare soil, and 0.19 for concrete. Finally, $25 \%$ to $75 \%$ percentile of $k B^{-1}$ ranged from 13.1 to 16.3 for SAC and 4.1-4.5 for IZM.

The representative bulk surface temperatures $\left(T_{s}\right)$ were estimated based on bulk sensible heat transfer

$$
T_{s}=\frac{Q_{H} r_{a}}{\rho_{a} c_{p}}+\theta_{a}
$$

where $Q_{H}$ is the sensible heat flux $\left(\mathrm{W} \mathrm{m}^{-2}\right)$ and $\theta_{a}$ is potential temperature at the reference height $(\mathrm{K})$.

The net radiation was estimated from the sum of the shortwave and longwave radiation components. The downward shortwave radiation was measured at each site. The upward shortwave radiation was measured at SAC, but it was estimated for IZM based on the surface albedo. The surface albedo at $\operatorname{IZM}(0.16)$ was the weighted mean of each land cover. We used the measured albedo at IZM for paved roads $(\alpha=0.07$; fraction is 0.12$)$, grasses $(\alpha=0.21$; fraction is 0.22 ), bare soil ( $\alpha=0.19$; fraction is 0.07$)$, and a pond ( $\alpha=0.07$; fraction is 0.06) and literature-based albedo (Oke, 1978) for trees ( $\alpha=0.17$; fraction is 0.52$)$ and buildings $(\alpha=0.16$; fraction is 0.01 ). The downward longwave radiation was based on the measurements at the roof of the building at the Osaka Prefecture University in Sakai (Ando and Ueyama, 2017). The upward longwave radiation was estimated by the Stefan-Boltzmann law using the estimated bulk surface temperatures from Eq. 6. We used a literature-based emissivity: 0.95 of urban canopy for SAC (Oke et al., 2017) and 0.97 of forests for IZM (Arya, 2001; Oke et al., 2017).

The storage heat flux and anthropogenic heat flux were estimated based on previously established methods (Ando and Ueyama, 2017). The storage heat flux for SAC was estimated by the Objective Hysteresis Model (Grimmond et al., 1991) whereas those for IZM was the energy balance equation assuming the energy imbalance is negligible. The anthropogenic heat flux was estimated by multiple regression based on inventories (Kayaba et al., 2010) for SAC (details are shown in Ando and Ueyama, 2017) but was assumed to be negligible for IZM.

To apply the temperature decomposition method, we separately estimated the cooling effect during the daytime $\left(R_{s d}\right.$ $\left.>100 \mathrm{~W} \mathrm{~m}^{-2}\right)$ and nighttime $\left(R_{s d}<10 \mathrm{~W} \mathrm{~m}^{-2}\right)$. All terms in Eqs. 1 to 4 were calculated at the half-hourly timescale. Due to the complexity in nighttime turbulent fluxes, the value of $\beta$ at night was difficult to determine. Because the nighttime turbulent heat fluxes were generally small, contributions from term 3 in Eq. 1 were considered of negligible importance. Consequently, we determined that term 3 was zero at night. We excluded the data of $\Delta T s_{\text {calc }}$ when the absolute value of $(f+1)$ was less than 0.2.

To verify $\Delta T S_{\text {calc }}$ from the temperature decomposition method, we compared the surface temperature differences between the two sites based on two different methods. First, we used the surface temperature difference estimated based on Eq. $6\left(\Delta T s_{\text {bulk }}\right)$. The consistency between $\Delta T S_{\text {calc }}$ and $\Delta T s_{\text {bulk }}$ supports the linear assumption in the perturbation analysis; in other words, high-order terms could be considered negligible for explaining the temperature differences. Second, $\Delta T S_{\text {calc }}$ was compared with the surface temperature differences between SAC and IZM based on Eq. 6 and the satellite-based radiometric surface temperatures. We used cloud-free images from band 10 of Landsat-8, with a spatial resolution of $100 \mathrm{~m}$. The thermal images were obtained for a 2-km radius of the Sakai City Office and the area of Oizumi Ryokuchi. The brightness temperatures from the Landsat images were converted to surface temperatures based on Weng et al. (2004). The thermal images were available for only four days at 10:34, Japan Standard Time, in the study period: February 16, July 26, September 28, and October 14 in 2015.

\section{Results and discussion}

The temperature differences that were determined using the temperature decomposition method were consistent with those determined by other methods. The magnitudes of the cooling by the temperature decomposition method $\left(\Delta T_{\text {calc }}\right)$ were consistent with those estimated by the bulk equation $\left(\Delta T_{s_{b u l k}}\right)$ (Figs. 1, 2). The difference between $\Delta T_{\text {calc }}$ and $\Delta T_{\text {bulk }}$ was $0.5 \mathrm{~K}$ during the day and $0.2 \mathrm{~K}$ at night on an annual basis (Fig. 1). On a seasonal basis, the difference between $\Delta T_{\text {calc }}$ and $\Delta T s_{\text {bulk }}$ was $0.1-2.2 \mathrm{~K}$ during the daytime and $\sim 0.4 \mathrm{~K}$ at night (Fig. 2). The magnitude of daytime $\Delta T S_{\text {calc }}$ was comparable to those from the satellite-derived radiometric surface temperatures (Landsat-8). The satellite-based surface temperature differences between SAC and IZM $(=-3.9 \pm 0.1 \mathrm{~K}$; four-day mean and standard error $)$ were similar to the differences in the daytime $\Delta T S_{\text {calc }}(=-5.6 \pm 0.2 \mathrm{~K}$; Fig. 1a).

The enhanced heat transport efficiency (Fig. 3; Table 1) most strongly explained the daytime park surface cooling (Figs. 1a, 2a; Table 2) through park creation. The daytime and nighttime $r_{a}$ in the dense urban area were, on average, 2.9 and 2.4 times larger than those in the urban park, respectively (Fig. 3b; Table 1). On an annual basis, the daytime surface cooling achieved through park creation was estimated to be $5.6 \pm 0.2 \mathrm{~K}$ based on the temperature decomposition method (Fig. 1a; Table 2). Among the cooling components, the decreased $r_{a}$ solely contributed $4.5 \pm 0.1 \mathrm{~K}$ to the daytime park surface cooling.

The effective cooling owing to the decreased $r_{a}$ following park creation was apparent throughout the seasons (Fig. 2a; Table 2). The surface cooling owing to the decreased $r_{a}$ was $3.9-4.9 \mathrm{~K}$ throughout the year, which contributed $75-91 \%$ of the total surface cooling. Even in the summer when evapotranspiration was high (June to August; Table 1), the enhanced heat transport efficiency most strongly contributed to the daytime surface cooling (Fig. 2a). 

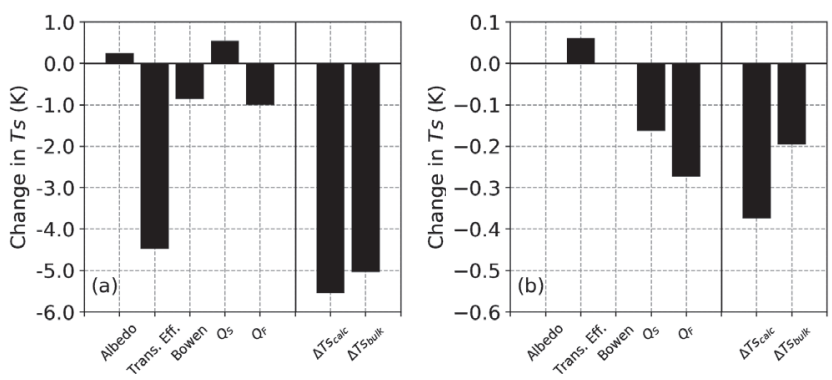

Fig. 1. The surface temperature $\left(T_{S}\right)$ change associated with the land use change from a dense urban built-up area to an urban park during the day (a) and night (b) on an annual basis. Based on the temperature decomposition method, the contributions in each component were calculated: albedo, heat transfer efficiency, Bowen ratio, storage heat flux $\left(Q_{S}\right)$, and anthropogenic heat flux $\left(Q_{F}\right)$. The values of $\Delta T S_{\text {calc }}$ and $\Delta T s_{\text {bulk }}$ represent the surface temperature differences estimated based on the temperature decomposition method and bulk transfer equation, respectively. The daytime was defined as the period when downward shortwave radiation was greater than $100 \mathrm{~W} \mathrm{~m}^{-2}$, whereas the nighttime was defined as when downward shortwave radiation was less than $10 \mathrm{~W} \mathrm{~m}^{-2}$.

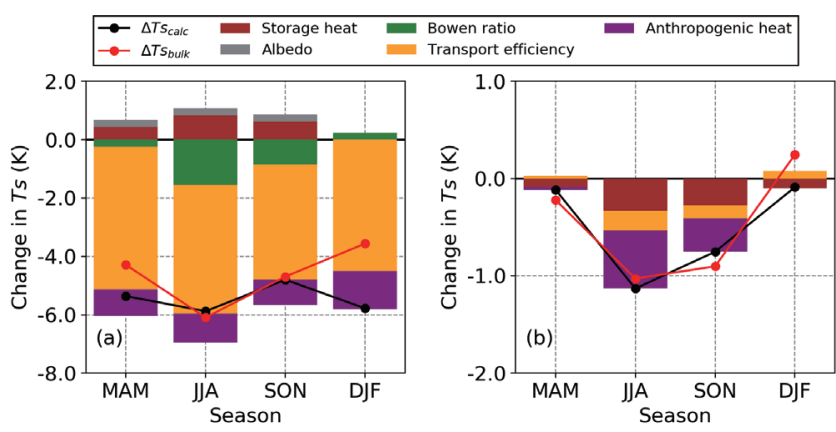

Fig. 2. Seasonal variations in surface temperature $(T s)$ change associated with the land use change from a dense urban built-up area to an urban park during the day (a) and night (b). We defined spring as March-May (MAM), summer as June-August (JJA), autumn as September-November (SON), and winter as December-February (DJF). The values of $\Delta T S_{\text {calc }}$ and $\Delta T S_{\text {bulk }}$ represent the surface temperature differences estimated based on the temperature decomposition method and bulk transfer equation, respectively. Daytime was defined as the period when downward shortwave radiation was greater than $100 \mathrm{~W} \mathrm{~m}^{-2}$, whereas nighttime was defined as when downward shortwave radiation was less than $10 \mathrm{~W} \mathrm{~m}^{-2}$.

Although the latent heat flux in the park was 2.2 times larger than that in the urban area in the summer (Table 1), the daytime cooling by evapotranspiration $(1.6 \pm 0.1 \mathrm{~K})$ was smaller than the cooling due to the decreased $r_{a}(4.4 \pm 0.2 \mathrm{~K})$ in the summer (Fig. 1a). This result indicates that the enhanced heat transport achieved through greening mitigated the daytime UHI effect more effectively than enhanced transpiration capacity, even in the summer.

The ineffective heat transfer in the urban area was caused by the so-called scale effect. In general, large elements develop a greater surface boundary layer near the elements (e.g., a microscale laminar layer on each building facet) than small elements, where heat transfer is controlled by molecular

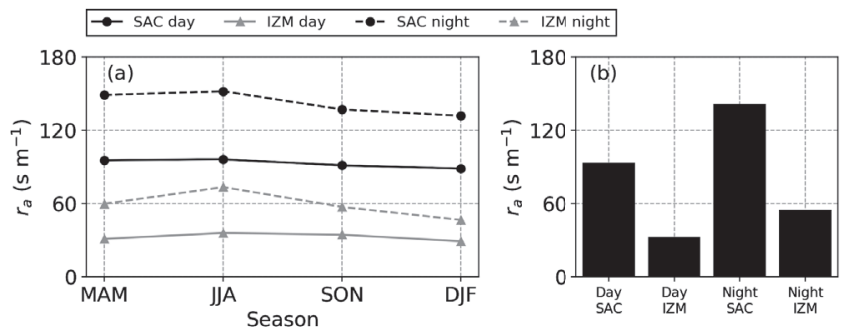

Fig. 3. Seasonal variation (a) and annual mean (b) of the aerodynamic resistance to heat $\left(r_{a}\right)$ in the dense urban built-up area (SAC) and the urban park (IZM) during the day and night. We defined spring as March-May (MAM), summer as June-August (JJA), autumn as September-November (SON), and winter December-February (DJF). Daytime was defined as the period when downward shortwave radiation was greater than $100 \mathrm{~W} \mathrm{~m}^{-2}$, whereas nighttime was defined as when downward shortwave radiation was less than $10 \mathrm{~W} \mathrm{~m}^{-2}$.

diffusion (Kanda et al., 2007; Sakai et al., 2012). Thus, larger elements have smaller heat transfer efficiency. Urban elements, such as buildings, are larger in scale as they are often several meters, whereas leaves are less than a few centimeters. Consequently, urban surface temperatures are higher than those for vegetative surface during the daytime.

Changing urban structures to vegetative surfaces increases $z_{h}$ and promotes heat diffusion from the surface to the atmosphere. The importance of $z_{h}$ has not been well evaluated on a city scale but has recently been predicted to play a major role in the UHI effect based on the earth system model (Zhao et al., 2014). Previous observations have only discussed the effect of evapotranspiration or tree shade in terms of daytime park cooling (Hamada and Ohta, 2010; Spronken-Smith and Oke, 1998; Sugawara et al., 2016). Our results based on direct flux measurements strongly suggest that increasing $z_{h}$ is the most effective option for mitigating the daytime UHI effect (Sakai et al., 2012).

The disappearance of anthropogenic heat flux most strongly contributed to nighttime cooling, with contributions of $0.3 \pm 0.1 \mathrm{~K}$ on an annual basis (Fig. 1b; Table 2). The nighttime anthropogenic heat flux was estimated to be, on average, $15 \pm 0.1 \mathrm{~W} \mathrm{~m}^{-2}$ in the urban area (Table 1). This difference indicates that anthropogenic heat directly increased the urban surface temperatures, and indirectly increased the surface temperatures by reducing the temperature differences between the air and surface with increasing nighttime air temperatures.

The decreased heat storage following park creation was the second most important component for explaining nighttime cooling on an annual basis (Fig. 1b). The magnitude of the nighttime negative $Q_{S}$ was, on average, $7 \mathrm{~W} \mathrm{~m}^{-2}$ larger in the urban area than in the park (Table 1). Stored heat in urban structures during the daytime could contribute to reradiation at night. On an annual basis, the total nighttime cooling achieved through park creation was $0.4 \pm 0.1 \mathrm{~K}$, of which decreasing heat storage contributed $0.2 \pm 0.1 \mathrm{~K}$. Large storage heat fluxes have been measured in urban areas (e.g., Ando and Ueyama, 2017; Grimmond and Oke, 1999; Moriwaki and Kanda, 2004), representing a major mechanism of the surface UHI effect at night (Zhao et al., 2014). Therefore, decreased heat storage by 
Table 1. Seasonal and annual means of albedo $(\alpha)$, aerodynamic resistance to heat $\left(r_{a}\right)$, Bowen ratio $(\beta)$, storage heat flux $\left(Q_{S}\right)$, anthropogenic heat flux $\left(Q_{F}\right)$, and latent heat flux $(L E)$ for the urban site (SAC) and the urban park site (IZM). The error value with plus/ minus sign denotes the standard error, and $n$ denotes the sample number. We defined spring as March-May, summer as June-August, autumn as September-November, and winter as December-February. Daytime was defined as the period when downward shortwave radiation was greater than $100 \mathrm{~W} \mathrm{~m}^{-2}$, whereas nighttime was defined as when downward shortwave radiation was less than $10 \mathrm{~W} \mathrm{~m}$.

\begin{tabular}{|c|c|c|c|c|c|c|c|c|c|c|c|c|c|}
\hline \multirow[b]{2}{*}{ Period } & & \multicolumn{4}{|c|}{$\alpha$} & \multicolumn{4}{|c|}{$r_{a}\left(\mathrm{~s} \mathrm{~m}^{-1}\right)$} & \multicolumn{4}{|c|}{$p$} \\
\hline & & \multicolumn{2}{|c|}{ SAC } & \multicolumn{2}{|l|}{ IZM } & \multicolumn{2}{|c|}{ SAC } & \multicolumn{2}{|c|}{ IZM } & \multicolumn{2}{|c|}{ SAC } & \multicolumn{2}{|c|}{ IZM } \\
\hline \multirow[t]{2}{*}{ Spring } & Day & $0.19 \pm 0.00$ & $n=1851$ & $0.16^{* 1}$ & & $96 \pm 1.09$ & $n=888$ & $31 \pm 0.40$ & $n=775$ & $3.50 \pm 0.19$ & $n=379$ & $1.68 \pm 0.06$ & $n=626$ \\
\hline & Night & & & & & $149 \pm 3.34$ & $n=805$ & $60 \pm 2.32$ & $n=322$ & $0.05 \pm 0.05$ & $n=145$ & $-1.17 \pm 0.06$ & $n=169$ \\
\hline \multirow[t]{2}{*}{ Summer } & Day & $0.18 \pm 0.00$ & $n=1866$ & $0.16^{* 1}$ & & $96 \pm 0.94$ & $n=923$ & $36 \pm 0.47$ & $n=827$ & $2.11 \pm 0.10$ & $n=500$ & $0.48 \pm 0.01$ & $n=769$ \\
\hline & Night & & & & & $152 \pm 2.63$ & $n=788$ & $74 \pm 1.88$ & $n=286$ & $0.16 \pm 0.03$ & $n=181$ & $-0.44 \pm 0.03$ & $n=152$ \\
\hline \multirow[t]{2}{*}{ Autumn } & Day & $0.20 \pm 0.00$ & $n=1403$ & $0.16^{* 1}$ & & $91 \pm 1.14$ & $n=731$ & $35 \pm 0.65$ & $n=361$ & $2.97 \pm 0.19$ & 323 & $0.84 \pm 0.04$ & $n=336$ \\
\hline & Night & & & & & $137 \pm 2.70$ & $n=900$ & $57 \pm 2.65$ & $n=158$ & $-0.12 \pm 0.05$ & & $-1.07 \pm 0.07$ & $n=113$ \\
\hline \multirow[t]{2}{*}{ Winter } & Day & $0.22 \pm 0.00$ & $n=1654$ & $0.16^{* 1}$ & & $89 \pm 1.03$ & $n=687$ & $29 \pm 0.42$ & $n=$ & $4.38 \pm 0.21$ & & $2.60 \pm 0.08$ & $n=672$ \\
\hline & Night & & & & & $132 \pm 2.43$ & $n=1057$ & $47 \pm 1.08$ & $n=902$ & $-0.29 \pm 0.06$ & $n=151$ & $-1.34 \pm 0.04$ & $n=493$ \\
\hline \multirow[t]{2}{*}{ Annual } & Day & $0.20 \pm 0.00$ & $n=6774$ & $0.16^{* 1}$ & & $93 \pm 0.53$ & $n=3229$ & $33 \pm 0.24$ & $n=2729$ & $3.08 \pm 0.08$ & $n=1478$ & $1.43 \pm 0.03$ & $n=2403$ \\
\hline & Night & & & & & $142 \pm 1.39$ & $n=3550$ & $55 \pm 0.88$ & $n=1668$ & $-0.04 \pm 0.02$ & $n=617$ & $-1.13 \pm 0.03$ & $n=927$ \\
\hline & & \multicolumn{4}{|c|}{$Q_{S}\left(\mathrm{~W} \mathrm{~m}^{-2}\right)$} & \multicolumn{3}{|c|}{$Q_{F}\left(\mathrm{~W} \mathrm{~m}^{-2}\right)$} & & \multicolumn{4}{|c|}{$L E\left(\mathrm{~W} \mathrm{~m}^{-2}\right)$} \\
\hline \multicolumn{2}{|l|}{ Period } & \multicolumn{2}{|c|}{ SAC } & \multicolumn{2}{|c|}{ IZM } & \multicolumn{2}{|c|}{ SAC } & \multicolumn{2}{|l|}{ IZM } & \multicolumn{2}{|c|}{ SAC } & \multicolumn{2}{|c|}{ IZM } \\
\hline \multirow[t]{2}{*}{ Spring } & Day & $106 \pm 2.4$ & $n=1851$ & $120 \pm 4.9$ & & $24 \pm 0.10$ & $n=1851$ & $0^{* 2}$ & & $44 \pm 2.7$ & $n=523$ & $108 \pm 2.8$ & $n=635$ \\
\hline & Night & $-50 \pm 0.3$ & 2341 & $-45 \pm 1.5$ & & $14 \pm 0.16$ & $n=2341$ & $0^{* 2}$ & & $12 \pm 0.9$ & 391 & $18 \pm 1.1$ & $n=249$ \\
\hline \multirow[t]{2}{*}{ Summer } & Day & $108 \pm 2.3$ & $n=1866$ & $84 \pm 3.7$ & & $27 \pm 0.14$ & $n=1866$ & $0^{* 2}$ & & $87 \pm 3.5$ & 538 & $193 \pm 3.3$ & $n=770$ \\
\hline & Night & $-45 \pm 0.2$ & $n=1927$ & $-43 \pm 1.5$ & $n=215$ & $12 \pm 0.14$ & $n=1927$ & $0^{* 2}$ & & $23 \pm 2.1$ & $n=364$ & $21 \pm 1.4$ & $n=215$ \\
\hline \multirow[t]{2}{*}{ Autumn } & Day & $78 \pm 2.4$ & $n=1403$ & $86 \pm 4.7$ & $n=338$ & $23 \pm 0.13$ & $n=1403$ & $0^{* 2}$ & & $59 \pm 3.4$ & $n=369$ & $128 \pm 3.8$ & $n=338$ \\
\hline & Night & $-49 \pm 0.3$ & $n=2356$ & $-47 \pm 2.0$ & $n=140$ & $13 \pm 0.14$ & $n=2356$ & $0^{* 2}$ & & $10 \pm 0.8$ & $n=460$ & $31 \pm 2.5$ & $n=140$ \\
\hline \multirow[t]{2}{*}{ Winter } & Day & $61 \pm 1.8$ & $n=1659$ & $76 \pm 3.2$ & $n=489$ & $32 \pm 0.04$ & $n=1659$ & $0^{* 2}$ & & $27 \pm 1.7$ & $n=383$ & $46 \pm 1.1$ & $n=699$ \\
\hline & Night & $-50 \pm 0.2$ & $n=3412$ & $-40 \pm 0.8$ & $n=691$ & $20 \pm 0.19$ & $n=3412$ & $0^{* 2}$ & & $8 \pm 0.5$ & $n=562$ & $18 \pm 0.7$ & $n=836$ \\
\hline \multirow[t]{2}{*}{ Annual } & Day & $90 \pm 1.2$ & $n=6779$ & $92 \pm 2.1$ & $n=2149$ & $27 \pm 0.07$ & $n=6779$ & $0^{* 2}$ & & $56 \pm 1.6$ & $n=1813$ & $120 \pm 1.8$ & $n=2442$ \\
\hline & Night & $-49 \pm 0.1$ & $n=10036$ & $-42 \pm 0.6$ & $n=1277$ & $15 \pm 0.09$ & $n=10036$ & $0^{* 2}$ & & $12 \pm 0.6$ & $n=1777$ & $20 \pm 0.6$ & $n=1440$ \\
\hline
\end{tabular}

${ }^{* 1}$ The value of albedo was assumed as 0.16 for the IZM site

${ }^{* 2}$ Anthropogenic heat flux was assumed to be negligible for the IZM site.

Table 2. Seasonal and annual means of the surface temperature $(\mathrm{K})$ change associated with the land use change from a dense urban built-up area to an urban park during the day and night. Based on the temperature decomposition method, the contributions in each component were calculated: albedo $(\alpha)$, aerodynamic resistance to heat $\left(r_{a}\right)$, Bowen ratio $(\beta)$, storage heat flux $\left(Q_{S}\right)$, and anthropogenic heat flux $\left(Q_{F}\right)$. The values of $\Delta T s_{\text {calc }}$ and $\Delta T s_{\text {bulk }}$ represent the surface temperature differences estimated based on the temperature decomposition method and bulk transfer equation, respectively. Daytime was defined as the period when downward shortwave radiation was greater than $100 \mathrm{~W} \mathrm{~m}^{-2}$, whereas nighttime was defined as when downward shortwave radiation was less than $10 \mathrm{~W} \mathrm{~m}$. The error with the plus/minus sign denotes standard error, and $n$ denotes the sample number.

\begin{tabular}{|c|c|c|c|c|c|c|c|c|c|}
\hline Period & & $\Delta \alpha$ & $\Delta r_{a}$ & $\Delta \beta$ & $\Delta Q_{S}$ & $\Delta Q_{F}$ & $\Delta T S_{\text {calc }}$ & $\Delta T s_{b u l k}$ & $n$ \\
\hline \multirow[t]{2}{*}{ Spring } & Day & $0.24 \pm 0.05$ & $-4.89 \pm 0.23$ & $-0.24 \pm 0.18$ & $0.44 \pm 0.29$ & $-0.92 \pm 0.03$ & $-5.36 \pm 0.40$ & $-4.29 \pm 0.30$ & 90 \\
\hline & Night & & $0.12 \pm 0.11$ & & $-0.09 \pm 0.13$ & $-0.14 \pm 0.16$ & $-0.11 \pm 0.14$ & $-0.22 \pm 0.14$ & 29 \\
\hline \multirow[t]{2}{*}{ Summer } & Day & $0.24 \pm 0.03$ & $-4.39 \pm 0.18$ & $-1.56 \pm 0.08$ & $0.83 \pm 0.20$ & $-1.00 \pm 0.03$ & $-5.88 \pm 0.26$ & $-6.09 \pm 0.28$ & 155 \\
\hline & Night & & $-0.20 \pm 0.10$ & & $-0.33 \pm 0.14$ & $-0.60 \pm 0.12$ & $-1.13 \pm 0.19$ & $-1.03 \pm 0.19$ & 39 \\
\hline \multirow[t]{2}{*}{ Autumn } & Day & $0.25 \pm 0.06$ & $-3.94 \pm 0.25$ & $-0.85 \pm 0.18$ & $0.62 \pm 0.34$ & $-0.87 \pm 0.04$ & $-4.80 \pm 0.37$ & $-4.69 \pm 0.30$ & 61 \\
\hline & Night & & $-0.13 \pm 0.25$ & & $-0.28 \pm 0.33$ & $-0.34 \pm 0.38$ & $-0.75 \pm 0.52$ & $-0.90 \pm 0.52$ & 7 \\
\hline \multirow[t]{2}{*}{ Winter } & Day & $0.28 \pm 0.06$ & $-4.73 \pm 0.26$ & $0.24 \pm 0.19$ & $-0.25 \pm 0.32$ & $-1.32 \pm 0.04$ & $-5.78 \pm 0.50$ & $-3.56 \pm 0.35$ & 50 \\
\hline & Night & & $0.18 \pm 0.22$ & & $-0.10 \pm 0.13$ & $-0.16 \pm 0.15$ & $-0.09 \pm 0.06$ & $0.25 \pm 0.06$ & 86 \\
\hline \multirow[t]{2}{*}{ Annual } & Day & $0.25 \pm 0.02$ & $-4.49 \pm 0.11$ & $-0.85 \pm 0.08$ & $0.54 \pm 0.14$ & $-1.00 \pm 0.02$ & $-5.55 \pm 0.18$ & $-5.04 \pm 0.17$ & 356 \\
\hline & Night & & $0.06 \pm 0.12$ & & $-0.16 \pm 0.08$ & $-0.27 \pm 0.09$ & $-0.37 \pm 0.08$ & $-0.20 \pm 0.08$ & 161 \\
\hline
\end{tabular}

urban greening should be able to mitigate the second strongest cause of the nighttime surface UHI.

\section{Conclusion}

Continuous flux measurements with the temperature decomposition method successfully explained the biophysical controls on the surface cooling in the urban park, and thus, could provide useful strategies for urban planning. Based on our analyses, effective arrangements of vegetation in urban areas can mitigate the surface UHI effect through enhanced heat transport efficiency. Enhanced heat transport efficiency achieved through urban greening could improve human thermal comfort and mitigate the health impacts of heatwaves during hot summers. Although this study revealed the potential cooling mechanism in terms of surface temperatures, the relationships between surface and air temperatures are known to be complex (Oke et al., 2017); thus, further studies on the effects on air temperature are important challenges that need to be addressed.

\section{Acknowledgments}

We thank the people of the Sakai City Office for supporting the measurements, and Dr. Hiroyuki Kaga of the Osaka Prefecture 
University for supporting the analysis. The measurements were partly supported by the Sumitomo Foundation (143205), the Organization for Landscape and Urban Green Infrastructure (87), and the JSPS KAKENHI, Grant Number 18H03362. Eddy covariance and supporting environmental data are freely available from the corresponding author's website (http://atmenv.envi. osakafu-u.ac.jp/data/sakai_data/) or through emailing M. Ueyama (ueyama@envi.osakafu-u.ac.jp). We also thank two anonymous reviewers and the editor for their constructive comments.

\section{References}

Ando T, Ueyama M, 2017: Surface energy exchange in a dense urban built-up area based on two-year eddy covariance measurements in Sakai, Japan. Urban Climate 19, 155-169.

Arya SP, 2001: Introduction to Micrometeorology second edition, Academic Press, New York, pp.420.

Bright RM, Zhao K, Jackson RB, Cherubini F, 2015: Quantifying surface albedo and other direct biogeophysical climate forcings of forestry activities. Global Change Biology 21, 3246-3266.

Cao C, Lee X, Liu S, Schultz N, Xiao W, Zhang M, Zhao L, 2016: Urban heat island in China enhanced by haze pollution. Nature Communications 7, 12509.

Chen L, Dirmeyer P, 2016: Adapting observationally based metrics of biogeophysical feedbacks from land cover/land use change to climate modeling. Environmental Research Letters 11, 034002, doi:10.1088/1748-9326/11/3/034002.

Chen X, Su Y, Li D, Huang G, Chen W, Chen S, 2012: Study on the cooling effects of urban parks on surrounding environments using Landsat TM data: A case study in Guangzhou, southern China. International Journal of Remote Sensing 33, 5889-5914.

Garratt JR, 1994: The atmospheric boundary layer. Cambridge University Press, New York, NY, pp. 316.

Grimmond CSB, Cleugh HA, Oke TR, 1991: An objective urban heat storage model and its comparison with other scheme. Atmospheric Environment 25, 311-326.

Grimmond CSB, Oke TR, 1999: Heat storage in urban areas; local-scale observations and evaluation of simple model. Journal Applied Meteorology 38, 922-940.

Hamada S, Ohta T, 2010: Seasonal variations in the cooling effect of urban green areas on surrounding urban areas. Urban Forest and Urban Greening 9, 15-24.

Ichinose T, Shimodozono K, Hanaki K, 1999: Impact of anthropogenic heat on urban climate in Tokyo. Atmospheric Environment 33, 3897-3909.

Juang J-Y, Katul G, Siqueira M, Stoy P, Novick K, 2007: Separating the effects of albedo from eco-physiological changes on surface temperature along a successional chronosequence in the southeastern United States. Geophysical Research Letters 32, L21408.

Kanda M, Kanega M, Kawai T, Moriwaki R, 2007: Roughness Lengths for Momentum and Heat Derived from Outdoor Urban Scale Models. Journal of Applied Meteorology and Climatology 46, 1067-1079.

Kanda M, Inagaki A, Miyamoto T, Gryschka M, Raasch S, 2013: A New Aerodynamic Parametrization for Real Urban Surfaces. Boundary-Layer Meteorology 148, 357-377.

Kayaba N, Aoyagi T, Takahashi S, 2010: Estimation of anthropogenic heat using multiple regression analysis. Weather Service Bulletin 77, 137-153 (in Japanese).

Kent CW, Grimmond S, Gatey D, 2017: Aerodynamic roughness parameters in cities: inclusion of vegetation. Journal of Wind
Engineering \& Industrial Aerodynamics 169, 168-176.

Kolokotroni M, Giridharan R, 2008: Urban heat island intensity in London: An investigation of the impact of physical characteristics on changes in outdoor air temperature during summer. Solar Energy 82, 986-998.

Kormann R, Meixner FX, 2001: An analytical footprint model for non-neutral stratification. Boundary-Layer Meteorology 99, 207-224.

Landsberg HE, 1981: The Urban Climate. Academic Press, New York, NY, pp. 275.

Lee X, Goulden ML, Hollinger DY, Barr A, Black TA, Bohrer G, Bracho R, Drake B, Goldstein A, Gu L, Katul G, Kolb T, Law BE, Margolis H, Meyers T, Monson R, Munger W, Oren R, Paw U KT, Richardson AD, Schmid HP, Staebler R, Wofsy S, Zhao L, 2011: Observed increase in local cooling effect of deforestation at higher latitudes. Nature 479, 384-387.

Ma Y, Menenti M, Feddes R, Wang J, 2008: Analysis of the land surface heterogeneity and its impact on atmospheric variables and the aerodynamic and thermodynamic roughness length. Journal of Geophysical Research 113, D08113.

Moriwaki R, Kanda M, 2004: Seasonal and diurnal fluxes of radiation, heat, water vapor, and carbon dioxide over a suburban area. Journal of Applied Meteorology 43, 1700-1710.

Oke TR, 1978: Boundary Layer Climates. Psychology Press, New York, NY, pp.464.

Oke TR, Mills G, Christen A, Voogt JA, 2017: Urban Climates. Cambridge University Press, Cambridge, pp.546.

Sakai S, Nakamura M, Furuya K, Amemura N, Onishi M, Iizawa I, Nakata J, Yamaji K, Asano R, Tamotsu K, 2012: Sierpinski's forest: New technology of cool roof with fractal shapes. Energy and Buildings 55, 28-34.

Spronken-Smith RA, Oke TR, 1998: The thermal regime of urban parks in two cities with different summer climates. International Journal of Remote Sensing 19, 2085-2104.

Spronken-Smith RA, Oke TR, Lowry WP, 2000: Advection and the surface energy balance across an irrigated urban park. International Journal of Climatology 20, 1033-1047.

Stoy PC, Katul GG, Siqueira MBS, Juang J-Y, Novick KA, McCarthy HR, Oishi AC, Uebelherr JM, Kim H-S, Oren R, 2006: Separating the effects of climate and vegetation on evapotranspiration along a successional chronosequence in the southeastern US. Global Change Biology 12, 1-21.

Sugawara H, Shimizu S, Takahashi H, Hagiwara S, Narita K, Mikami T, Hirano T, 2016: Thermal influence of a large green space on a hot urban environment. Journal of Environmental Quality 45, 125-133.

Taha H, 1997: Urban climates and heat islands: albedo, evapotranspiration, and anthropogenic heat. Energy and Buildings 25, 99-103.

Ueyama M, Ando T, 2016: Diurnal, weekly, seasonal, and spatial variabilities in carbon dioxide flux in different urban landscapes in Sakai, Japan. Atmospheric Chemistry and Physics 16, 14727-14740.

Weng Q, Lu D, Schubring J, 2004: Estimation of land surface temperature-vegetation abundance relationship for urban heat island studies. Remote Sensing of Environment 89, 467-487.

Zhao L, Lee X, Smith RB, Oleson K, 2014: Strong contributions of local background climate to urban heat islands. Nature 511, 216-219.

Zhou D, Zhang L, Li D, Huang D, Zhu C, 2016: Climate-vegetation control on the diurnal and seasonal variations of surface urban heat islands in China. Environmental Research Letters 11, 074009, doi:10.1088/1748-9326/11/7/074009 